\title{
A Rapid Microscopic Method for the Confirmation of Rhinoviruses in Cell Culture
}

\author{
Gary P. Leonardi Marie-Laure Desormeaux
}

Department of Pathology and Laboratories, Nassau University Medical Center, East Meadow, N.Y., USA

\section{Key Words}

Culture confirmation $\cdot$ Fluorescent antibodies $\cdot$ Rhinovirus

\begin{abstract}
Objective: Culture-confirmation of rhinovirus is done using acid lability testing, a laborious and time-consuming method which delays the reporting of patient results by $1-2$ days. A fluorescent monoclonal antibody pool (Light Diagnostics Pan-Enterovirus Blend; Millipore Inc., Temecula, Calif., USA) developed to identify various enterovirus isolates in culture was recently reported to also cross-react with rhinoviruses. We evaluated the use of this cross-reacting antibody, used in tandem with non-cross-reacting enterovirus antibodies $\left(D^{3}\right.$ IFA; Diagnostic Hybrids Inc., Athens, Ohio, USA) to rapidly identify rhinoviruses in cell culture. Methods: Microscope slides were prepared from cell cultures of 11 rhinovirus clinical isolates and a variety of other respiratory viruses. Slides were stained using both enterovirus antibody pools and examined for fluorescent activity. Results: Positive fluorescence was observed in all the rhinovirus isolates tested using the pan-enterovirus antibody blend, but yielded negative results when stained using the $D^{3}$ antibodies. Both antibody products produced positive fluorescence for enterovirus isolates and produced negative results when a variety of other respiratory viruses were examined. Conclusion: Staining
\end{abstract}

suspected rhinovirus isolates with each antibody pool affords a rapid means of identifying rhinoviruses and distinguishing them from enteroviruses, without the need for acid lability testing.

Copyright $\odot 2010$ S. Karger AG, Basel

Rhinoviruses are small, non-enveloped RNA viruses of the family picornaviridae, and comprise over 100 known serotypes [1]. Varying numbers and serotypes of this virus may circulate at any one time, producing substantial, upper respiratory 'common cold' symptoms in human infection [1].

Identification of rhinoviruses has been traditionally done using cultures of fibroblast MRC- 5 and WI-38 cells [1-4]. Spin-amplified, multichamber slides of Ohio HELA cells and anti-rhinovirus type 2 polyclonal serum have also been utilized to rapidly identify viral antigen [5].

Rhinovirus culture sensitivity is limited. Numerous factors, including short-term shedding, extreme lability, culture cell type, incubation temperature and the need to gently shake cultures during incubation, contribute to limited rhinovirus isolation [2-5]. When isolated in culture, rhinovirus and the enterovirus cytopathic effect (CPE) resemble each other. Differentiation of rhinovirus-

\section{KARGER}

Fax +4161306 1234 E-Mail karger@karger.ch www.karger.com (c) 2010 S. Karger AG, Basel

$0300-5526 / 10 / 0536-0426 \$ 26.00 / 0$

Accessible online at:

www.karger.com/int
Dr. Gary P. Leonardi

Department of Pathology and Laboratories

Nassau University Medical Center, 2201 Hempstead Tnpk., Box 47

East Meadow, NY 11554 (USA)

Tel. +1 516572 8711, Fax +1 516572 6409, E-Mail leonardi@ numc.edu 
es and enteroviruses can be made on the basis of acid lability, where the former is inactivated in a low $\mathrm{pH}$ environment [1-4]. This process is laborious and time consuming, which delays the reporting of patient results by 2 days or more.

Molecular nucleic acid detection methods, particularly polymerase chain reaction (PCR), have extended the scope of rhinovirus illness to include lower respiratory tract disease, e.g. pneumonia and the exacerbations of asthma $[4,6]$.

Although PCR is considered more sensitive than culture, one study demonstrated the lack of PCR sensitivity for serotypes 59 and 69 when compared with the latter [7]. Also, heightened PCR sensitivity may hinder the proper association of PCR-identified rhinovirus RNA with infectious virus production and clinical symptoms of respiratory illness. In one study, subjects providing multiple respiratory samples were identified as rhinovirus-positive by PCR for approximately 100 days before, during and after clinical symptoms were documented [4].

The genetic diversity among rhinoviruses, along with their potential to diagnostically cross-react with other picornavirus family members may preclude the development of an accurate, specific PCR technique to detect all rhinoviruses directly in patient specimens. Sensitivity/ specificity issues, along with high reagent costs and the need for specialized equipment and training limit the widespread use of rhinovirus molecular techniques $[4,6$, 7]. Despite these obstacles, the potential benefits of viral detection in lower respiratory tract disease will necessitate the continued development and improvement of these molecular assays.

For the present, traditional rhinovirus cell culture techniques, including confirmatory acid lability methods are employed in many diagnostic laboratories. Our investigation describes a new culture-confirmatory technique, using fluorescent monoclonal antibodies to identify rhinoviruses. As compared to traditional acid lability methods, fluorescent antibody confirmation is inexpensive to perform, technically less time consuming and shortens patient result time.

The utility of commercially prepared fluorescent monoclonal antibodies for the confirmation of enteroviruses in cell culture was recently assessed [3]. One product (LD; Light Diagnostics Pan-Enterovirus blend; Millipore Inc., Temecula, Calif., USA) demonstrated false positive results when staining other picornaviruses, including rhinovirus isolates, while another product $\left(\mathrm{D}^{3}\right.$ IFA; Diagnostic Hybrids, Inc., Athens, Ohio, USA) did not produce these false positive results.
Table 1. Evaluation of Light Diagnostics (LD) and Diagnostic Hybrids (DHI) enterovirus fluorescent antibody pools for the identification of rhinoviruses in cell culture

\begin{tabular}{llll}
\hline Virus & LD & DHI & Confirmation $^{1}$ \\
\hline Rhinovirus $^{2}$ & + & - & acid lability \\
Coxsackie A9 $_{\text {Coxsackie B2 }}$ & + & + & neutralization \\
Echovirus 9 & + & + & neutralization \\
Influenza A and B & + & + & neutralization \\
Parainfluenza 1-3 & - & - & immunofluorescence \\
Adenovirus type 2 & - & - & immunofluorescence \\
RSV & - & - & immunofluorescence \\
& & &
\end{tabular}

${ }^{1}$ Positive confirmation of enterovirus was done by using neutralization techniques with LBM antisera pools. Immunofluorescence was done using $\mathrm{D}^{3}$ fluorescent monoclonal antibodies (DHI). Acid lability testing was performed to confirm the rhinovirus isolates.

${ }^{2}$ A total of 11 clinical rhinovirus isolates was presently studied.

We stained 11 rhinovirus isolates, obtained from clinical specimens over a 3-year period with both these enterovirus antibody products. Rhinoviruses were obtained by thawing previously collected and preserved clinical patient isolates. All viral isolates were stored at ultra-low temperatures (Jewett Inc., Buffalo, N.Y., USA). Isolates were confirmed as rhinoviruses using acid lability techniques as previously described $[1,2]$. Isolates were inoculated into MRC-5 fibroblast tube cultures (Viromed Inc., Minnetonka, Minn., USA), placed on a stationary rack and incubated at $34^{\circ}$. Tubes were examined on alternate days for the presence of CPE using an inverted light microscope (Nikon TMS; Nikon Inc., Garden City, N.Y., USA). Positive cultures were then prepared for fluorescent microscopy. Aliquots $(0.1 \mathrm{ml})$ of positive cultures were used to make 2 'cell spots' on glass slides using a Cytospin 3 centrifuge (Thermo Scientific, Kalamazoo, Mich., USA). The resulting slide preparation of virus-infected cells available for antibody staining were fixed in cold acetone for $10 \mathrm{~min}$ and allowed to air-dry.

Other clinical isolates (adenovirus type 2, parainfluenza types $1-3$, influenza types $A$ and $B$, respiratory syncytial virus, coxsackie A9, echovirus type 9, coxsackie B2) were inoculated in rhesus monkey kidney cell culture tubes (DHI, Athens, Ga., USA) and processed as above to be used as positive and negative control material. Viral identification of the enterovirus isolates (coxsackie A9, coxsackie B2, echovirus type 9) was confirmed using neutralization techniques with LBM enteroviral anti- 
body pools [8]. The other respiratory virus isolates were confirmed using their appropriate fluorescent monoclonal antibodies (DHI).

Staining of cellular spots followed manufacturer instructions (Light Diagnostics Pan-Enterovirus Blend; Millipore Inc., and $D^{3}$ IFA, Diagnostic Hybrids Inc.) and the spots were examined using a Nikon episcopic microscope equipped with a $460-490 \mathrm{~nm}$ excitation filter (Nikon Inc.), allowing FITC to emit an apple-green fluorescence.

Staining results for the LD and DHI products is summarized in table 1 . The LD product produced positive fluorescent activity when staining the 11 rhinovirus slides. In comparison, the DHI product produced negative results. Both antibody pools demonstrated positive fluorescent activity when tested on the slide preparations of the enterovirus isolates coxsackie A9, coxsackie B2 and echovirus type 9 , but negative results when staining a variety of other respiratory agents (adenovirus, influenza A and $B$, parainfluenza $1-3$, respiratory syncytial virus). Definitive identities of these agents were confirmed by staining with their appropriate antibody reagents.

In the present investigation, a pan-enterovirus fluorescent antibody pool (LD), produced 'false positive' fluorescence in rhinovirus isolates, whereas another enterovirus fluorescent antibody product (DHI) did not.
These findings may result from the viral antigens or epitopes that each product's monoclonal antibodies are directed against. In the DHI product, antibodies are directed against the well conserved, VP1 enterovirus antigen. In contrast, the monoclonal antibodies of the LD product have not been characterized as to the particular antigens or epitopes recognized (Light Diagnostics PanEnterovirus Blend package insert).

The LD product has also been found to cross-react with other picornavirus members, reovirus and parechovirus [3]. Differentiation of these viruses from rhinovirus in the clinical setting can be made as they rarely grow in routine clinical specimens, require inoculation monkey kidney or other specialized cultures (Vero cells, Graham 293), and often require sub-passage and/or cellular treatment with additives (trypsin, sialic acid) prior to inoculation $[9,10]$. Rhinoviruses are identifiable in fibroblast cultures, producing little recognizable CPE in routinely inoculated monkey kidney cells.

When employed in tandem, the use of the LD and DHI antibody products easily identifies rhinovirus while ruling out enterovirus in clinical isolates. The subsequent reductions in laboratory costs, technical labor and delays in patient result reporting make this technique an important tool for use in the clinical laboratory.

\section{References}

1 Landry ML: Rhinoviruses; in Murray PR, Baron MA, Jorgensen Pfaller EJ, Yolken RH (eds): Manual of Clinical Microbiology. Washington, ASM Press, 2003, pp 14181426.

2 Swenson P: Differentiation of rhinoviruses from enteroviruses; in Isenberg HJ (ed): Clinical Microbiology Procedure Handbook. Washington, American Society for Microbiology, 1992, pp 8.13.1-8.13.3.

$3 \mathrm{Vu}$ M, Yeh E, Schnurr DP: Comparison of sensitivity and specificity of a new enterovirus group reactive monoclonal antibody reagent from Diagnostic Hybrids to reagents from Chemicon and DAKO (abstract S-46). 23rd Annual Clinical Virology Symposium, Clearwater, 2007.

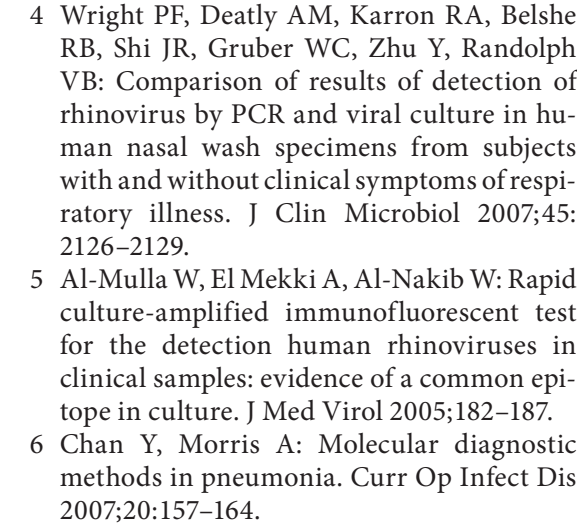

7 Do DH, Laus S, Leber A, Marcon MJ, Jordan JA, Martin JM, Wadowsky RM: A one-step real-time PCR assay for rapid detection of rhinovirus. J Mol Diagn 2010;12:102-108.

8 Lim KA, Benyesh-Melnick M: Typing of virus by combination of antiserum pools. Application of typing enteroviruses. J Immunol 1960;84:309-317.

9 Yamamoto M, Abe K, Kuniyuri K, Kunii E, Ito F, Kasama Y, Yoshioka Y, Noda M: Epidemic of human parechovirus type 3 in $\mathrm{Hi}$ roshima City, Japan in 2008. Jpn J Infect Dis 2009;62:391-398.

10 Rubin L, Evans HE, Spickard A: Reovirus infection in human volunteers. Am J Hyg 1963; 77:29-37. 